\title{
Depression, Anxiety, and Stress In The Time of COVID-19 Pandemic In Kurdistan Region, Iraq
}

\author{
Niaz Mustafa Kamal \\ Pediatric Nursing \\ Technical Institute of Sulaimani \\ Sulaimani Polytechnic University \\ Sulaimani, Iraq \\ niaz.Kamal@spu.edu.iq
}

\author{
Nasih Othman \\ Health, Kurdistan Institute for Strategic Studies and Scientific Research \\ Sulaimani, Iraq \\ nasih.othman@kissr.edu.krd
}

\begin{tabular}{l} 
Article Info \\
\hline Special Issue on \\
Coronavirus (COVID-19) \\
DOI: \\
10.24017/covid.5 \\
Article history: \\
Received : 02 May 2020 \\
Accepted : 04 May 2020 \\
\hline
\end{tabular}

Keywords:

Depression, Anxiety, Stress, DASS-21, Kurdistan Region, COVID-19

\section{ABSTRACT}

The global spread of the COVID-19 pandemic, its threat to people's health and its indirect impacts through the subsequent measures taken by governments to control the disease have led to uncertainty and huge disruption in the way people used to live with a negative impact on mental health and wellbeing. The current study estimate prevalence of the common mental health disorders among a sample of the adult population in the Kurdistan Region during the pandemic. Through an online survey using DASS-21 to measure depression, anxiety, and stress data of 548 adult participants were collected during April 2020 and analyzed. The sample was mainly from Sulaimani (89\%), mean age was 37.9 (SD 13.5) and male/female ratio was 1. Prevalence of any severity levels of depression, anxiety, and stress was $45 \%$, $47 \%$, and $18 \%$ respectively. In regression analysis, notably female sex was a significant independent factor for higher levels of depression (coefficient 1.89, p<0.05), anxiety (coefficient 2.19, $p<0.001$ ), and stress (coefficient 1.52, $p<0.05$ ). Postgraduate education and other occupations were also significantly associated with depression (coefficient 3.81, $p<0.05$; coefficient $2.39, \quad p<0.05$ respectively), anxiety (coefficient 2.92, $p<0.05$; coefficient $4.1, p<0.001$ respectively) and stress (coefficient 3.83, $p<0.001$; coefficient 4.1, $p<0.001$ respectively). The study indicates high levels of common mental health disorders during the pandemic and calls for public health measures to promote the mental health and resilience of the population. 


\section{INTRODUCTION}

The novel coronavirus disease infection (COVID-19) started in first started in China in December 2019 and a few months spread to almost all countries of the world. The infection was declared by the World Health Organization as a global pandemic in March 2020[1]. As of the end of April, over 3.2 million cases of the infection and over 326,000 deaths have been reported globally with the majority of infections and deaths reported from western Europe and North America [2]. The unprecedented pandemic has led many countries to declare it as a public health emergency with the implementation of far-reaching measures to curb its spread including travel restrictions, emergency response procedures, and even entire country lockdowns. Apart from the fear and uncertainty about the spread of infections, people faced other challenges that could impact their mental health and psychological well-being including movement restriction, changes in their lifestyle, living conditions and jobs, closure of schools [3]. The unexpected and sudden nature of the outbreak and the infectious power of the virus, will inevitably would probably cause people anxiety, stress, and other mental health symptoms. Indeed, fear of contacting individuals who are possibly infected by COVID-19 has been reported [4]. The emergence of the COVID-19 with its vicious pandemic and rapid spread has exacerbated fears worldwide leading to mental health problems, and even stigma and discrimination in some cases[5,6]. Therefore it imperative to investigate and understand the psychological status of the public during this troubled and destructive time[7]. In addition to its direct impact on the health of people who are infected with a relatively high mortality rate, measures implemented to control COVID-19 could impose broad psychological impacts on human societies. A review of the literature concludes that COVID-19 pandemic has negatively impacted mental health outcomes such as depression, anxiety stress, stress, posttraumatic stress, anger, and feeling of social isolation and loneliness [8]. Health workers are reported to be more vulnerable, and other factors such s loss of income and duration of quarantine were associated with the degree of psychological impact [8]. With the stretching of the restrictive measures and resultant economic hardship, it is feared that such a negative impact could continue and have long-lasting implications. The pandemic is only a few months old and its yet early to understand its true impact, and generally there are no much literature on the psychology and mental health status of the general public during the peak of the COVID-19 epidemic[9]. Like Iraq and neighboring countries, Kurdistan region was affected by the epidemic which gradually led to lockdown in March and April and widespread disruption of people's life and activates. We are not aware of studies done recently to assess common mental health condition during the pandemic. Therefore the purpose of this study was to investigate levels of depression, anxiety and stress among a sample of the adult population who responded to our online survey.

\section{METHODS AND MATERIALS}

This quantitative survey was conducted online from 14 to 18 April 2020 after a month of the lockdown due to coronavirus pandemic in Kurdistan Region. A total of 548 adult participants (aged 18 and above) took part in the survey. The survey was created in Survey Monkey (www.surveymonkey.com/) and the link was send withinvitations to potential participants through online social media (Facebook) and were eligible after reading the purpose of the study, the written consent part in the first section of the online survey. If they agreed then they could proceed to complete the questionnaire. The main part of the questionnaire was the Kurdish translation of the depression, anxiety, and stress scale (DASS-21) which is a standard 21 items (statements) tool with three sub-scales of 7 items for each of depression, anxiety, and stress [10]. Each statement is rated on a scale of $4(0=$ did not apply to me at all, and $3=$ applied to me most of the time). The scores of each subscale are summed and multiplied by 2 to represent the total for the subscale. Higher scores indicate higher levels of the condition. The scores for each subscale are then categorized to indicate the level of each condition from mild to extremely severe. To check reliability of the scale we calculated Cronbach's alpha for the entire scale and the three subscales. In our study, alpha was $0.92,0.8,0.79,0.83$ for the 
entire scale, depression scale, anxiety scale, and stress scale respectively all of which indicate god internal consistency and reliability. In addition to DASS-21, participants were also requested to answer a few socio-demographic questions such as age, sex, occupation, education, and residence. Answering the questionnaire lasts 5 minutes on average by only clicking the checkbox for answering. This study has been approved by the presidency of Sulaimani Polytechnic University.

Stata version 12 was used for statistical analysis after the data were automatically recorded in the Excel file of the survey and then imported to the Stata. Demographic variables were described using frequencies and percentages. The DASS-21 scores were first presented in means and standard deviation then we categorized them according to the scale guidelines[10] into 5 levels of severity (none, mild, moderate, severe and extremely severe), then for further analysis, the levels were dichotomized to presence and absence of the condition (i.e. we combining all 4 severity levels to one category). Bivariate association of socio-demographic characteristics with the prevalence of depression, anxiety, and stress was evaluated using a Chi-square test. Finally, we used multiple regressions to investigate the association of the total scores of each subscale with the Sociodemographic variables.

\section{RESULTS}

A total of 548 people completed the online survey. The mean age of the participants was 37.9 (SD 13.5) years with a minimum age of 18 and the maximum age of 81 years. Males and females similarly participated in the study $(49.6 \%$ vs. $50.4 \%)$ respectively. One third of the participants were married $(75.5 \%)$. The sample was biased towards higher levels of education where $(70.4 \%)$ had college/institute education and $(15.3 \%)$ had postgraduate education. The majority of the participants were from Sulaimani city $(88.9 \%)$ while the remaining was from Erbil (11.1\%). See Table 1.

Table 1: Socio-demographic factors among participants $(n=548)$

\begin{tabular}{|c|c|c|}
\hline Characteristics & Number & Percentage \\
\hline Age group (Mean \pm Std Deviation ) & & $37.9 \pm 13.5$ \\
\hline $18-25$ & 146 & $26.8 \%$ \\
\hline 26-35 & 110 & $20.1 \%$ \\
\hline $36-45$ & 114 & $20.8 \%$ \\
\hline $46-55$ & 132 & $24.1 \%$ \\
\hline$>55$ & 46 & $8.4 \%$ \\
\hline \multicolumn{3}{|l|}{ Sex } \\
\hline Male & 272 & $49.6 \%$ \\
\hline Female & 275 & $50.4 \%$ \\
\hline \multicolumn{3}{|l|}{ Marital state } \\
\hline Married & 414 & $75.5 \%$ \\
\hline Not married & 134 & $24.5 \%$ \\
\hline \multicolumn{3}{|l|}{ Education level } \\
\hline Basic/high School & 78 & $14.2 \%$ \\
\hline Institute/College & 386 & $70.4 \%$ \\
\hline Postgraduate & 84 & $15.3 \%$ \\
\hline \multicolumn{3}{|l|}{ Residence } \\
\hline Sulaimani & 487 & $88.9 \%$ \\
\hline
\end{tabular}




\begin{tabular}{ccc}
\hline Erbil & 61 & $11.1 \%$ \\
\hline Occupation & & \\
\hline Student/unemployed & 122 & $22.3 \%$ \\
\hline Health/Medical & 130 & $23.7 \%$ \\
\hline Other occupations & 296 & $54.0 \%$ \\
\hline
\end{tabular}

In terms of employment, $23.7 \%$ worked in health/medical professions, $54 \%$ had other jobs, and $22.3 \%$ were not employed. Figure 1 shows a more detailed distribution of the employment categories.

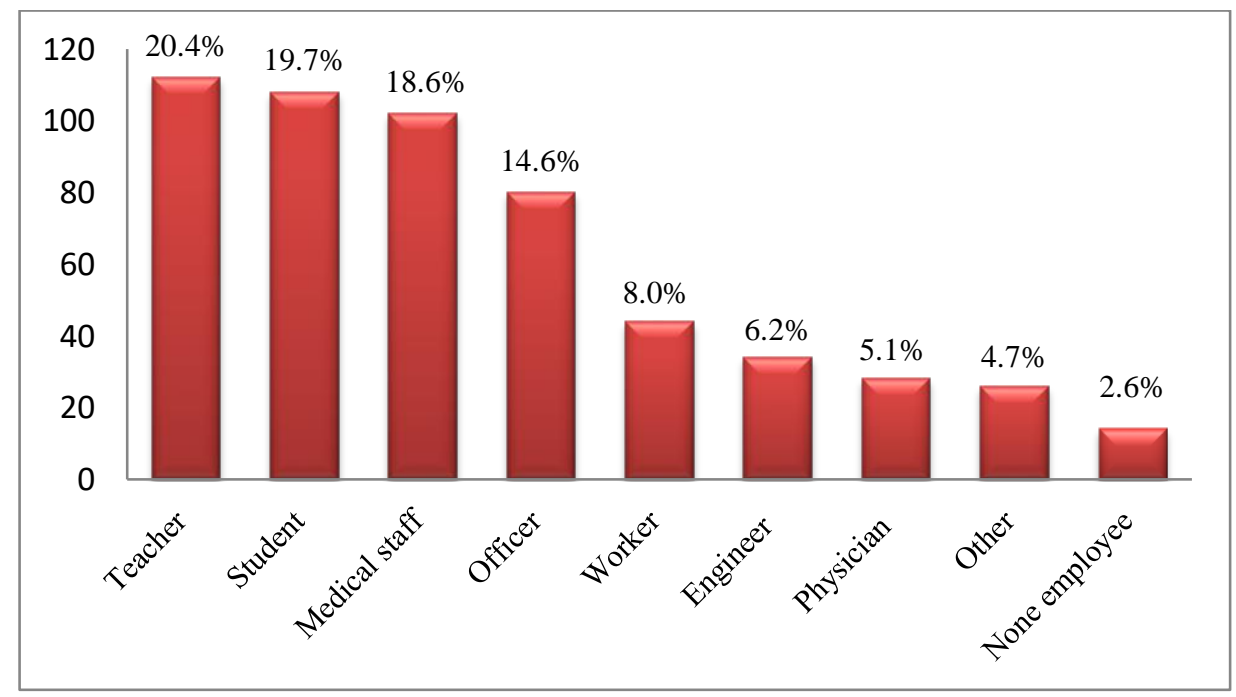

Figure 1: Distribution of participants' occupation

\subsection{Scores and prevalence of depression, anxiety, and stress}

Table 2 shows mean score of the three subscales for depression, anxiety, and stress, overall and by sex. Depression scores for females were significantly higher than males (Mean 8.1, SD 6.2 vs. Mean 7.0, SD 6.8, p<0.05). The same was true for anxiety where mean score for females was 11.4 (SD 7.6) vs. 7.7 (SD 7.9) for males $(\mathrm{p}<0.05)$. There was no significant difference between males and females in relation to stress cores.

Table 2: Mean scores for depression, anxiety, and stress, overall and by sex

\begin{tabular}{ccccc}
\hline \multirow{2}{*}{ Scale } & $\begin{array}{c}\text { All }(\mathbf{n}=\mathbf{5 4 8}) \\
\text { Mean }(\mathbf{S D})\end{array}$ & $\begin{array}{c}\text { Male }(\mathbf{n}=\mathbf{5 1}) \\
\text { Mean }(\mathbf{S D})\end{array}$ & $\begin{array}{c}\text { Female }(\mathbf{n}=\mathbf{1 4 3}) \\
\text { Mean }(\mathbf{S D})\end{array}$ & t, p-value \\
\hline Depression & $9.3(7.6)$ & $7.0(6.8)$ & $8.1(6.2)$ & $-2.14,0.04$ \\
\hline Anxiety & $7.6(6.5)$ & $7.7(7.9)$ & $11.4(7.6)$ & $-2.03,0.04$ \\
\hline Stress & $9.3(7.0)$ & $9.1(7.4)$ & $9.5(6.5)$ & $-0.56,0.57$ \\
\hline DASS-211 & $26.2(19.1)$ & $24.8(20.02)$ & $27.6(18.06)$ & $-1.78,0.08$ \\
\hline
\end{tabular}

Table 3 shows the severity levels of the three conditions. In terms of severity levels, $55.1 \%$ had no depression, $17.5 \%$ had mild, 18.9 had moderate and $8.4 \%$ had severe/extremely severe symptoms of depression (i.e. $44.9 \%$ had depression of any severity). As for anxiety, $52.9 \%$ were normal, $9.5 \%$ had mild symptoms, $26.3 \%$ had moderate symptoms and $11.3 \%$ had severe/extremely severe symptoms (i.e. $47.1 \%$ had anxiety of any severity). Stress was less common with $8 \%$ mild, $7.3 \%$ moderate, and $2.2 \%$ severe/extremely severe stress (i.e. $17.5 \%$ of the respondents showed the stress of any severity). 
Table 3: Prevalence of severity levels of depression, anxiety and stress $(n=548)$

\begin{tabular}{cccc}
\hline Severity level & Depression (\%) & Anxiety (\%) & Stress (\%) \\
\hline Normal & $302(55.1)$ & $290(52.9)$ & $452(82.5)$ \\
\hline Mild & $96(17.5)$ & $52(9.5)$ & $44(8.0)$ \\
\hline Moderate & $104(18.9)$ & $144(26.3)$ & $40(7.3)$ \\
\hline $\begin{array}{c}\text { Severe/ Extremely } \\
\text { severe }\end{array}$ & $46(8.4)$ & $62(11.3)$ & $12(2.2)$ \\
\hline
\end{tabular}

\subsection{Prevalence of depression, anxiety, and stress by socio-demographic factors}

Table 4 analyses the prevalence of the three conditions by various socio-demographic characteristics. For depression, sex, education, and occupation were significant factors. Females showed a higher prevalence of depression than males $(50 \%$ vs. $39.7 \%$, p <0.05). In terms of education, the highest prevalence of depression was found among postgraduate respondents with a prevalence of $57.1 \%$. In terms of employment, the prevalence of depression was highest among the unemployed and students $(52.5 \%)$. As for anxiety, again sex and occupation were significant factors. The prevalence of anxiety was $54.4 \%$ in females compared to $39.7 \%$ in males $(\mathrm{p}<0.05)$. The highest prevalence of anxiety was found among people with other occupations $(51.4 \%)$ as compared to $(38.5 \%)$ among health professionals. The prevalence of stress was also highest among people in other professions $(22.3 \%)$ and those with postgraduate education $(21.4 \%)$. See Table 4.

Table 4: Analysis of prevalence depression, anxiety and stress as a binary variable by various characteristics of participants

\begin{tabular}{|c|c|c|c|c|c|c|}
\hline Characteristics & $\begin{array}{l}\text { Depression } \\
246(44.9 \%)\end{array}$ & & $\begin{array}{l}\text { Anxiety } \\
258(47.1 \%)\end{array}$ & & $\begin{array}{l}\text { Stress } \\
96(17.5 \%)\end{array}$ & \\
\hline Sex & Number (\%) & $\chi^{2}, \mathbf{p}$ & Number (\%) & $\chi^{2}, \mathbf{p}$ & Number (\%) & $\chi^{2}, \mathbf{p}$ \\
\hline Male & $108(39.7)$ & $5.87,0.02$ & $108(39.7)$ & $11.8,0.001$ & $44(16.2)$ & $0.68,0.4$ \\
\hline Female & $138(50)$ & & $0(54.4)$ & & $52(18.8)$ & \\
\hline \multicolumn{7}{|l|}{ Age in years } \\
\hline $18-25$ & $68(46.6)$ & $1.39,0.85$ & $66(45.2)$ & $5.4,0.25$ & $26(17.8)$ & $7.4,0.1$ \\
\hline $26-35$ & $50(45.5)$ & & $52(47.3)$ & & $10(9.1)$ & \\
\hline $36-45$ & $48(42.1)$ & & $62(54.4)$ & & $24(21.1)$ & \\
\hline $46-55$ & $62(47.0)$ & & $62(47.0)$ & & $26(19.7)$ & \\
\hline$>55$ & $18(39.1)$ & & $16(34.8)$ & & $10(21.7)$ & \\
\hline \multicolumn{7}{|l|}{ Marital state } \\
\hline Married & $178(43.0)$ & $2.46,0.12$ & $67(50.0)$ & $0.6,0.44$ & $27(20.2)$ & $0.85,0.36$ \\
\hline $\begin{array}{l}\text { Not } \\
\text { married }\end{array}$ & $68(50.8)$ & & $191(46.1)$ & & $69(16.7)$ & \\
\hline \multicolumn{7}{|l|}{ Education level } \\
\hline $\begin{array}{l}\text { Basic/secon } \\
\text { dary }\end{array}$ & $32(41.0)$ & $6.12,0.05$ & $36(46.2)$ & $2.36,0.3$ & $4(5.1)$ & $9.9,0.007$ \\
\hline $\begin{array}{l}\text { Institute/co } \\
\text { llege }\end{array}$ & $166(43.0)$ & & $176(45.6)$ & & $74(19.2)$ & \\
\hline $\begin{array}{l}\text { Postgradua } \\
\text { te }\end{array}$ & $48(57.1)$ & & $46(57.8)$ & & $18(21.4)$ & \\
\hline
\end{tabular}

\section{Occupation}




\begin{tabular}{|c|c|c|c|c|c|c|}
\hline $\begin{array}{l}\text { Unemploye } \\
\text { d/student }\end{array}$ & $64(52.5)$ & \multirow[t]{3}{*}{$9.6,0.008$} & $56(45.1)$ & \multirow[t]{3}{*}{$6.1,0.05$} & $14(11.5)$ & \multirow[t]{3}{*}{$10.2,0.006$} \\
\hline $\begin{array}{l}\text { Health/med } \\
\text { ical }\end{array}$ & $44(33.9)$ & & $50(38.5)$ & & $16(12.3)$ & \\
\hline $\begin{array}{l}\text { Other } \\
\text { occupation } \\
\text { s }\end{array}$ & $46(46.6)$ & & $152(51.4)$ & & $66(22.3)$ & \\
\hline \multicolumn{7}{|l|}{ Residence } \\
\hline Sulaimani & 217 (44.6) & $0.19,0.66$ & $227(46.6)$ & \multirow[t]{2}{*}{$\begin{array}{l}0.39 \\
0.54\end{array}$} & $43(17.0)$ & \multirow[t]{2}{*}{$0.68,0.4$} \\
\hline Erbil & $29(47.5)$ & & $31(50.8)$ & & $13(21.3)$ & \\
\hline
\end{tabular}

Table 5 shows the results of multiple regression for the scores of each of depression, anxiety, and stress continuous outcomes and sex, age, education, marital status, occupation, and residence as risk factors. Female sex still remained the most important independent factor for higher levels of depression (coefficient 1.89, $\mathrm{p}<0.05$ ), anxiety (coefficient 2.19, $\mathrm{p}<0.001$ ), and stress (coefficient 1.52, $\mathrm{p}<0.05$ ). Postgraduate education (coefficient 3.81, $\mathrm{p}<0.05$ ) and other occupations (coefficient 2.39, $\mathrm{p}<0.05$ ) were also significantly associated with depression. As for anxiety, apart from female sex, postgraduate education (coefficient 2.92, $\mathrm{p}<0.05$ ) and other occupations (coefficient $4.1, \mathrm{p}<0.001$ ) were also significantly associated with anxiety. Same factors were significant for stress: postgraduate education (coefficient 3.83, $\mathrm{p}<0.001$ ) and other occupations (coefficient 4.1, $\mathrm{p}<0.001$ ).

Table 5: Regression analysis of factors associated with depression, analysis, and stress scores

\begin{tabular}{|c|c|c|c|c|c|c|c|c|c|}
\hline \multirow[t]{2}{*}{ Risk factor } & \multicolumn{3}{|c|}{ Depression score } & \multicolumn{3}{|c|}{ Anxiety score } & \multicolumn{3}{|l|}{ Stress score } \\
\hline & Coefficient & SE & $\mathbf{P}$ & Coefficient & SE & $\mathbf{P}$ & Coefficient & SE & $\mathbf{P}$ \\
\hline Sex- Male & Reference & & & Reference & & & Reference & & \\
\hline Sex- Female & 1.89 & 0.71 & 0.01 & 2.19 & 0.59 & $<0.001$ & 1.52 & 0.64 & 0.02 \\
\hline City: Sulaymaniyah & Reference & & & Reference & & & Reference & & \\
\hline City: Erbil & 1.45 & 1.0 & 0.15 & 1.63 & 0.86 & 0.06 & 1.59 & 0.92 & 0.09 \\
\hline Age(10 year interval) & -0.52 & 0.34 & 0.12 & -0.51 & 0.29 & 0.07 & -0.37 & 0.31 & 0.23 \\
\hline Job: unemployed & Reference & & & Reference & & & Reference & & \\
\hline Job: Health/medical & -1.3 & 1.14 & 0.25 & 1.31 & 0.96 & 0.18 & 1.55 & 1.03 & 0.13 \\
\hline Job: Other & 2.39 & 1.13 & 0.03 & 4.1 & 0.95 & $<0.001$ & 4.1 & 1.02 & $<0.001$ \\
\hline Marital: Not married & Reference & & & Reference & & & Reference & & \\
\hline Marital: Married & -0.51 & 0.81 & 0.53 & -0.90 & 0.69 & 0.19 & -0.92 & 0.73 & 0.21 \\
\hline $\begin{array}{l}\text { Education: } \\
\text { Basic/secondary }\end{array}$ & Reference & & & Reference & & & Reference & & \\
\hline $\begin{array}{l}\text { Education: } \\
\text { Institute/College }\end{array}$ & 1.29 & 0.96 & 0.18 & 0.01 & 0.82 & 0.99 & 1.98 & 0.88 & 0.02 \\
\hline Education: Postgraduate & 3.81 & 1.27 & 0.003 & 2.92 & 1.07 & 0.007 & 3.83 & 1.15 & 0.001 \\
\hline Constant & 7.53 & 1.28 & $<0.001$ & 5.34 & 1.09 & $<0.001$ & 5.48 & 1.16 & $<0.001$ \\
\hline
\end{tabular}

\section{DISCUSSION}

Our study which is unique of being undertaken at the time of the lockdown in the middle of the pandemic provides valuable findings on prevalence and factors associated with depression, anxiety, and stress. We found high levels of depression and anxiety among the study which is understandable although we do not know how much of this is actually contribute by the current situation. Our results conform with a study done on the general population in Italy showing that COVID-19 outbreak has had a psychological effect on the people [11]. We also found that females reported significantly higher prevalence and scores for depression, anxiety, and stress which is in the line with the study was done in Indian, reporting that women significantly have a high prevalence of depression, anxiety, and stress compared to the men [12]. On the other hand, a study done in Iran revealed only anxiety was higher in males than 
females while depression and stress were not significantly different [13]. Higher levels of education were significantly associated with depression, anxiety, and stress probably indicating that these people were more health-conscious concerned and worried both due to their existing situation and the difficulties brought about by the pandemic. These results are in line with a study from China reporting more psychological symptoms among people with higher education probably because of high self-awareness of their health [14], however, another study has not found any association between education and common mental health problems [15]. It notable in our study that health professionals had lower levels of the depression, anxiety, and stress than people with other occupations which could be partly explained by the fact the pandemic was mild in the region and with few hospitalizations and no pressure on the health care as seen in countries with large numbers of the infection and hospitalizations. A study from Singapore, a country quickly responded and controlled the pandemic, report's findings similar to our study [16]. We did not find significant associations between mental health problems and age and marital status although some studies have shown such association [13, 17]. During normal times younger ages may be more at risk of mental distress but the effect of the pandemic and the restrictive measures unanimously affected the population probably similarity affecting their mental health. The lockdown kept families together for longer hours at home and it would be interesting to know how this might have affected their mental health.

The current study is probably the first to investigate common mental health problems during the pandemic which a large sample that could provide meaningful analysis. However, the sample was convenient as the survey was made available through social media for volunteers to respond, and this might have caused selection bias. People who have participated were probably biased towards higher levels of education and, they were also people with more awareness and concerns about their health. Thus, the results might not be generalizable to the adult population. However, this is an inherent problem with online surveys where people are free to participate or not and researchers have no control over who participates. The results should be interpreted in the context of the current situation where people were under lockdown during the pandemic. We do not know the levels of anxiety, stress, and depression before the pandemic therefore we don't know whether there was an increase from prior levels or not. This requires further research to see how these rates might change over time, and also to explore how people feel the short-terms and long-term impact of the situation on their mental health.

\section{CONCLUSIONS}

Using a standard psychometric tool, the study showed a high prevalence of depression in the adult populations of Kurdistan Region during the COVID-19 pandemic and identified a number of significant factors associated with these mental health problems. The findings could serve as a baseline for future studies to assess the impact of the pandemic on mental health of the population. The study could also draw attention of researchers to this important and largely overlooked aspect of population health populations especially at these difficult times where the pandemic, the disruptive measures, and the financial hardship could all join to exert a more negative impact on mental health and wellbeing.

Increasing public awareness of depression, anxiety, and stress and coping strategies is essential to promote mental health. We believe that this and further research on this issue can help inform mental interventions to prevent and mitigate the negative mental health impact of the pandemic.

\section{ACKNOWLEDGMENT}

The authors wish to thank all the individuals who volunteered to participate in this online survey study and the presidency of Sulaimani Polytechnic University for their permission for completing this study. 


\section{REFERENCE}

[1] W. H. Organazayion, "Rolling updates of coronavirus disease (COVID_19). Available at: ," https://www.who.int/emergencies/diseases/novel-coronavirus-2019/events-as-they-happen Accessed on 29 April 2020.

[2] Worldmeter, "Coronavirus (COVID-19 pandemic. Available https://www.worldometers.info/coronavirus/\#countries. ," Worldmeter (2020). , p. Worldmeter (2020). Accessed on 29 April 2020.

[3] C. Wang, R. Pan, X. Wan, Y. Tan, L. Xu, C. S. Ho, et al., "Immediate Psychological Responses and Associated Factors during the Initial Stage of the 2019 Coronavirus Disease (COVID-19) Epidemic among the General Population in China," Int J Environ Res Public Health, vol. 17, Mar 62020.

[4] C.-Y. Lin, "Social reaction toward the 2019 novel coronavirus (COVID-19)," Social Health and Behavior, vol. 3, p. 1, 2020.

[5] C. K. T. Lima, P. M. M. Carvalho, I. Lima, J. Nunes, J. S. Saraiva, R. I. de Souza, et al., "The emotional impact of Coronavirus 2019-nCoV (new Coronavirus disease)," Psychiatry Res, vol. 287, p. 112915, May 2020.

[6] O. Hahad, D. A. Gilan, A. Daiber, and T. Munzel, "[Public Mental Health as One of the Key Factors in Dealing with COVID-19]," Gesundheitswesen, Apr 302020.

[7] Y. Wang, Y. Di, J. Ye, and W. Wei, "Study on the public psychological states and its related factors during the outbreak of coronavirus disease 2019 (COVID-19) in some regions of China," Psychol Health Med, pp. 1-10, Mar 302020.

[8] S. Rohr, F. Muller, F. Jung, C. Apfelbacher, A. Seidler, and S. G. Riedel-Heller, "[Psychosocial Impact of Quarantine Measures During Serious Coronavirus Outbreaks: A Rapid Review]," Psychiatr Prax, vol. 47, pp. 179-189, May 2020.

[9] C. Wang, P. W. Horby, F. G. Hayden, and G. F. Gao, "A novel coronavirus outbreak of global health concern," The Lancet, vol. 395, pp. 470-473, 2020.

[10] L. S. Lovibond PF, "Manual for the depression anxiety stress scales (2nd ed.)," Psychology Foundation: Sydney. , (1995)

[11] L. Moccia, D. Janiri, M. Pepe, L. Dattoli, M. Molinaro, V. De Martin, et al., "Affective temperament, attachment style, and the psychological impact of the COVID-19 outbreak: an early report on the Italian general population," Brain Behav Immun, Apr 202020.

[12] S. S. H. Kazmi, K. Hasan, S. Talib, and S. Saxena, "COVID-19 and Lockdwon: A Study on the Impact on Mental Health," Available at SSRN 3577515, 2020.

[13] S. Ashtari, A. Vahedian-Azimi, M. Moayed, F. Rahimibashar, S. Shojaei, and M. Pourhoseingholi, "Compare the severity of psychological distress among four groups of Iranian society in COVID-19 pandemic," 2020.

[14] Y. Zhang and Z. F. Ma, "Impact of the COVID-19 Pandemic on Mental Health and Quality of Life among Local Residents in Liaoning Province, China: A Cross-Sectional Study," Int J Environ Res Public Health, vol. 17, Mar 312020.

[15] J. Qiu, B. Shen, M. Zhao, Z. Wang, B. Xie, and Y. Xu, "A nationwide survey of psychological distress among Chinese people in the COVID-19 epidemic: implications and policy recommendations," General psychiatry, vol. 33, 2020.

[16] B. Y. Q. Tan, N. W. S. Chew, G. K. H. Lee, M. Jing, Y. Goh, L. L. L. Yeo, et al., "Psychological Impact of the COVID-19 Pandemic on Health Care Workers in Singapore," Ann Intern Med, Apr 62020.

[17] M. Dosil-Santamaria, M. Picaza-Gorrochategui, and N. Idoiaga-Mondragon, "Stress, anxiety, and depression levels in the initial stage of the COVID-19 outbreak in a population sample in the northern Spain," Cad. Saúde Pública, vol. 36, p. e00054020, 2020. 